\title{
HIGH-LEVEL-OF-DETAIL SEMANTIC 3D GIS FOR RISK AND DAMAGE REPRESENTATION OF ARCHITECTURAL HERITAGE
}

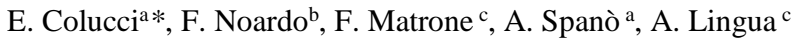 \\ ${ }^{a}$ Department of Architecture and Design (DAD) - Politecnico di Torino, Viale Mattioli 39, 10125 Torino (Italy) \\ (elisabetta.colucci@polito.it, antonia.spano@polito.it) \\ b Department of Urbanism - Delft University of Technology, Julianalaan 134, 2628 BL Delft (The Netherlands) \\ (f.noardo@tudelft.nl) \\ ${ }^{\mathrm{c}}$ Department of Environment Land and Infrastructure Engineering (DIATI) - Politecnico di Torino, Corso Duca degli Abruzzi 24, \\ 10129 Torino (Italy) (andrea.lingua@polito.it, francesca.matrone@polito.it)
}

Commission IV, WG IV/2

KEY WORDS: Cultural Heritage, Semantic 3D Model, Database, Risk, Segmentation, Standard Data Models

\begin{abstract}
:
The need to share information about architectural heritage effectively after a disaster event, in order to foster its preservation, requires the use of a common language between the involved actors and stakeholders. A database able to connect the architectural heritage representation with the data useful for hazard and risk analysis can thus be a powerful instrument. This paper outlines a methodology to represent 3D models of the architectural heritage, according to some existing standards data models, and relate their geometric features to the damage mechanisms that could occur after an earthquake. Among all the existing standard to represent cartographic, cultural heritage and hazard/risk information, respectively INSPIRE, CityGML, UNESCO, CIDOC-CRM, its extension MONDIS and the Getty Institute vocabularies, compliant to the CIDOC-CRM, have been taken into account. An INSPIRE extension has been proposed for increasing the level of detail (LoD) of the representation and improving the description of heritage buildings, adding some macro-elements and elements "feature types" connected with the damage mechanisms, identified in structural studies. The suggested method allows to archive, in a multi-scale database, 3D information with a very high level of detail about architectural heritage and can help structural engineers and conservator-restorers in preventing further damages through individuating useful targeted actions.
\end{abstract}

\section{INTRODUCTION}

The effectiveness of a shared information requires some common language to be known. For this reason, the representation of cities and landscapes must be structured following common data models and standard ontologies, in order to allow their easy communication and management. In particular, a shared information is important for supporting common policies and directives in order to reach common aims. Examples of such aims are declared in the "Sendai framework for disaster risk reduction" (UNISDR 2017), which was published by the United Nations for reducing losses and damages caused by disasters. Cultural heritage $(\mathrm{CH})$ is included in the document as object of risk. It is important to archive information and documentation of cultural heritage effectively to preserve it against disasters and to increase its resilience. The present work deals specifically with architectural heritage, which is included in cultural heritage definition and, in addition, holds some characteristics as a part of the city or landscape.

Some works have already studied the semantics useful to represent architectural heritage information through standard data models, but only few researches about information systems include the description of damage mechanisms of the building for archiving data about its structural behaviour.

The aim of this work is focused on the representation of the architectural elements including their 3D geometric features connected to the damage mechanisms. In particular the church type of building was taken into account.

For this study the specific updates of a dedicated Italian directive (Directive, 2011), described in section 3.2, and the existing standards about damage mechanisms description, used to structural analysis were considered, in order to gain an effective semantic and geometric interoperability easily providing information to structural engineers and further users of the database. The chosen data model was extended, adding the Macro-Elements and Elements feature types connected with the respective damage mechanisms.

\subsection{Existing standards for architectural heritage representation}

The existing standards for the representation of information concurring in the architectural heritage knowledge come from various fields. Some of the most critical ones are those available for the digital mapping, which is essential to represent the architecture in its context (being it urban, landscape or wider portions of land), and the cultural heritage, describing data about history, cultural value, artistic characteristics and further relevant connected issues.

The standard core ontology for representing $\mathrm{CH}$ is the ' $\mathrm{CIDOC}$ conceptual reference model' (CIDOC-CRM), developed by the International Committee for Documentation (CIDOC) of the International Council of Monuments (ICOM), now standard ISO 21127 (Doerr et al., 2007). Some extensions were developed in order to improve the usability of the CIDOC-CRM for different kind of cultural heritage. In particular, for this study we have to consider the 'Monument Damage Information System' (MONDIS) (Blaško et al., 2012, Cacciotti et al., 2013).

Moreover, some vocabularies are published by the Getty Institute, which are compliant with the CIDOC-CRM, and propose terms connected to cultural heritage, as premiere references for categorizing works of art, architecture, material

\footnotetext{
* Corresponding author
} 
culture, the names of artists or architects as well as the geographic categories. They are: The Art and Architecture Thesaurus (AAT), for terms describing works of art and architectures; the Thesaurus of Geographic Names (TGN), which, in contrast to GeoNames (structured database for toponyms) (http://www.geonames.org/), also includes historical denominations; the Union List of Artist Names (ULAN), for authors; and the Cultural Objects Name Authority (CONA), for the different denominations of a cultural item over time. The vocabularies are compliant with ISO and NISO standards for thesaurus construction and are also compliant with to other standards: CDWA (Categories for the Description of Works of Art); CCO (Cataloguing Cultural Objects); VRA Core (Visual Resources Association core categories); LIDO (Lightweight Information Describing Objects).

The Getty vocabularies can be effectively used in cataloguing, retrieval and linking because: each record has unique ID; the vocabularies are linked to each other; they share a core data structure.

In particular, for this study a part of the AAT will be considered for a shared definition of the parts of the architecture that will be managed through the proposed method.

On the other hand, in the field of geo-information, as it is well known, the main spread and used standards are: for urban areas, CityGML (http://www.opengeospatial.org/standards/citygml), which is an international standard data model published by the Open Geospatial Consortium for representing multiscale 3D information about city objects; and the INSPIRE data model (2007, to be compulsory adopted in Europe by 2020) (http://inspire.ec.europa.eu/data-model/approved/r4618$\mathrm{ir} / \mathrm{html} /$ ), which is part of the European Directive for reaching an interoperable cartography in Europe. This last one considers and includes some features of CityGML, especially in the definition of the data model regarding buildings.

However, these data models are aimed at the representation of wide portions of land, therefore they are limited in the level of detail and in the semantic definition useful to architectural heritage. Another standard concerning the information about buildings, the is the IFC (Industry Foundation Classes) for the BIM (Building information Model). This last one is directed to a higher level of detail in the representation, but it is specific for new buildings; it is therefore still difficult to employ it for historical buildings.

Some extensions of these standards have been proposed for increasing the level of detail and including architectural heritage in the maps: INSPIRE extensions (Fernandez-Freire et al., 2013), CityGML extensions (Costamagna, Spanò, 2012, Noardo, 2017).

\section{THE INSPIRE EXTENSION WITHIN RESCULT PROJECT}

The premise of the work here described is the development of a European Interoperable Database (EID) developed during the European project ResCult (Increasing Resilience of Cultural Heritage) (Chiabrando et al., 2018).

ResCult project (https://www.rescult-project.eu/) was funded (2016-2018) by the European Commission with the European Union Humanitarian Aid and Civil Protection, in the DG-ECHO program, in order to enhance the capability to prevent the impact of disasters (natural or man-made) on cultural heritage.

The EID might offer a unique framework and a supporting decision tool to understand the risk of damage to cultural heritage (included architectural heritage) as well as its impact on cohesion, sustainable cultural tourism and engagement with local communities in protecting the environment.

The EID manages a 3D European Heritage Map and helps in developing a disaster risk reduction strategy according to the
Sendai Framework principles (UNISDR 2017), to improve both prevention and resilience capacities.

\subsection{ResCult INSPIRE Extension}

During the first phases of ResCult project the INSPIRE data model and CityGML were considered according to completeness, updating, extension possibility and international acknowledgement.

INSPIRE was taken into account as regards the harmonized spatial information as reference for the European Community. CityGML was chosen for its specific semantics about city objects representation. Moreover, it includes the Level of Details (LoDs) concept, which foresee multiscale 2D and 3D representations of city and buildings. The granularity of LoDs can be enhanced (Biljecki et al., 2016) and further extended in order to represent more suitably the necessary architectural elements.

Finally, some existing standards about classifying risks and hazards were considered analysing recent documents of UNESCO (UNESCO, ICCROM, ICOMOSIUCN, 2010) and INSPIRE data model (CRED classification of Natural Disaster) (IRDR, 2014). The final ResCult classification of risks and hazards considers natural and man-made disasters.

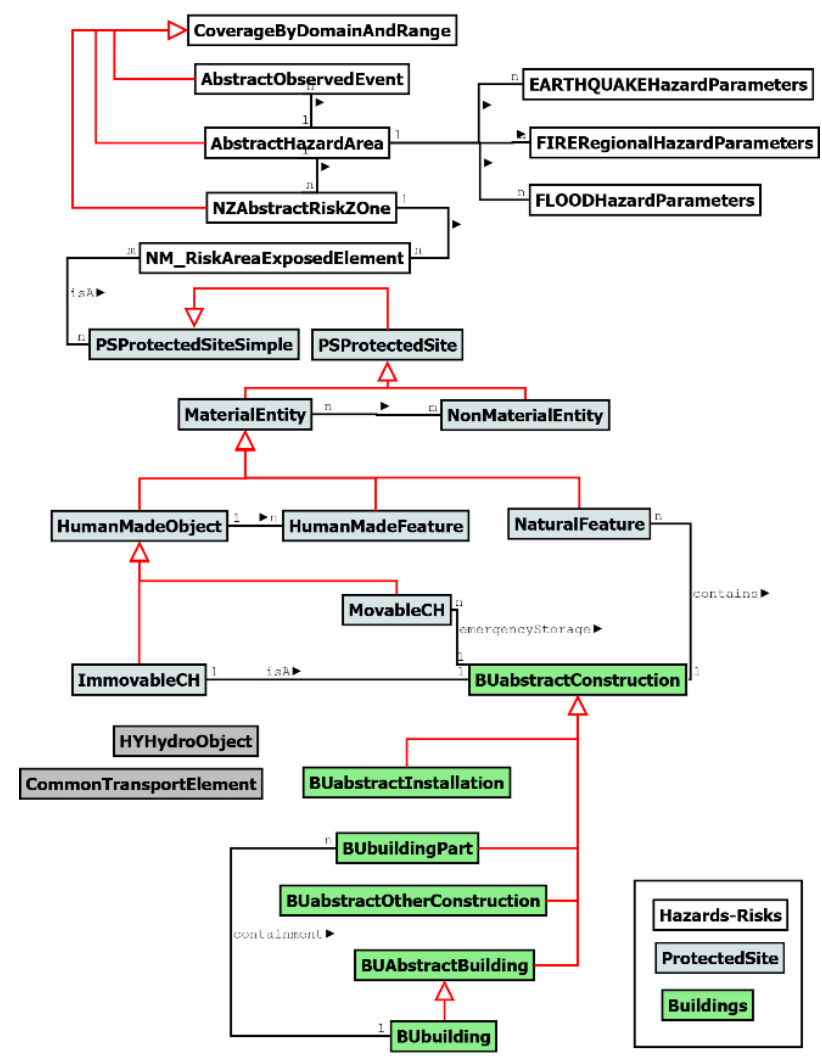

Figure 1. Simplified schema of the EID conceptual model (the red arrows symbolise the relations "inherit from", the black arrows the general relations, specified in each label).

The EID Conceptual Data Model was finally developed extending the INSPIRE data model (INSPIRE, 2013; INSPIRE, 2014), in order to operate in a unique and interoperable international framework. It deals in particular with three main parts of the INSPIRE data model: the first one is 'ProtectedSite' theme of the Annex I of the INSPIRE data model, for representing objects needing protection due to various reasons (ecological, biological, cultural) and legally acknowledged. This is the entity useful to describe cultural heritage, once it is suitably extended. Another part considered in the ResCult INSPIRE 
extension is the 'NaturalHazard' theme (Annex III), for connecting directly the object exposed to the risk and the description of the risk itself. Finally, the 'Building' theme (Annex III) is considered and extended, adding attributes and useful features to archive effective information for architectural heritage. The extension is described in more detail in (Chiabrando et al., 2018) and represented in Figure 1.

However, further improvements are needed to specifically represent different types of built heritage with a very high level of detail in order to better describe the structural behaviour of single elements, which is important for preventing damages in case, for example, of earthquakes, as stated by the updates of the Italian Directive (Model A-DC).

\section{THE DAMAGE ANALYSIS}

\subsection{Mapping to MONDIS}

Some parallel schemas describing the semantics of cultural heritage components, in association with damage and deterioration mechanisms, already exist. In particular, it is impossible to disregard the MONDIS (Monument Damage Information System) ontology. It is connected with the CIDOCCRM and it involves many objects also included in the portion of the INSPIRE data model as extended for the ResCult project and further detailed in the present study.

The language used for the definition of MONDIS is quite different from the INSPIRE one, since it is a Linked Open Data model, therefore represented in Ontology Web Language (OWL), aimed at the representation in Resource Description Framework (RDF) language of web sources. On the other hand, the INSPIRE data model is based on Geographic Markup Language (GML) technologies, useful to represent spatial and geographical data. However, the two representations are likely to meet in the web, so it is here provided a mapping between some class of MONDIS and the proposed extension of INSPIRE, so that it will be possible to foster the interoperability between the two kinds of representation and exploit the advantages derived from both. The mapped entities are briefly listed in Table 1.

\begin{tabular}{|l|l|}
\hline \multicolumn{1}{|c|}{ MONDIS class } & \multicolumn{1}{c|}{ INSPIRE extended data model class } \\
\hline Risk & $\begin{array}{l}\text { Components of the NaturalHazard theme of } \\
\text { INSPIRE, in particular to } \\
\text { naturalHazardClassification values }\end{array}$ \\
\hline Hazard & $\begin{array}{l}\text { Better defined in the features and attributes of } \\
\text { buildings and protected sites in the RESCULT } \\
\text { extension to INSPIRE }\end{array}$ \\
\hline Component & macroelement \\
\hline & element \\
\hline Mechanism & damageMechanism - mechanismType \\
\hline
\end{tabular}

Table 1. Mapping between the MONDIS classes and INSPIRE extension classes.

\subsection{The Italian Guideline/Directive of 09/02/2011}

In this research, a further extension of the ResCult data model is proposed to connect architectural heritage and the specific seismic hazard related to its structural behaviour. This approach has been pointed out by some works developed in collaboration with structural engineers and described in some recent international and national guidelines and directives about the issue (Lagomarsino et al., 2004, NIKER, 2010)

The more advanced guideline for this purpose is the Italian Directive of 09/02/2011 named 'Valutazione e riduzione del rischio sismico del patrimonio culturale con riferimento alle norme tecniche per le costruzioni di cui al D.M. 14/01/2008' (in English: 'Assessment and reduction of seismic hazard of cultural heritage with reference to the technical standards for constructions as in the Ministerial Decree of 14/01/2008'). It defines a classification of the most frequent structural damages based on the geometric, structural and architectural elements of the building. This Guideline was drafted "with the aim of specifying a path of knowledge, assessing a level of safety against seismic actions and designing of any interventions, conceptually similar to that envisaged for non-protected buildings, but appropriately adapted to the needs and peculiarities of cultural heritage" (Directive, 2011). Its purpose is to express, in the most objective way, an overall judgment on the safety and conservation guaranteed by the seismic improvement intervention.

In particular, the damage observation on the existing buildings, especially on the churches, has shown recurring behaviours that are linked to local damage and collapse mechanisms typical for the different architectural parts. These parts are defined as "macro-elements" (facade, nave, transept, etc.), namely elements or architectural parts in which the seismic behaviour is almost independent from the rest of the structure (Lagomarsino and Podestà, 2004 a) (Table 2). The direct observations of the effects of a seismic event on historical buildings have highlighted how the damage can be attributed to a limited number of damage mechanisms, which are conditioned by the shape, the characteristics of the construction materials and the state of conservation of the building.

The analysis of the detectable damage mechanisms, therefore, represents a method for the interpretation of the behaviour of the artefact and a possibility of forecasting the possible response on similar buildings.

According to these researches to perform the damage and vulnerability analyses (Giuffrè, 1993; Lagomarsino and Podestà, 2004) and thanks to the evaluation of a considerable number of churches case studies, the repetition in different situations of the same damage mechanism has been noticed in all buildings, laying the base for the definition of the Directive.

\begin{tabular}{|c|c|}
\hline Damage mechanisms & $\begin{array}{l}\text { Part of the } \\
\text { church }\end{array}$ \\
\hline $\begin{array}{l}1 \text { - OVERTURNING OF THE FACADE } \\
2 \text { - DAMAGE AT THE TOP OF FACADE } \\
3 \text { - SHEAR MECHANISMS IN THE } \\
4 \text { - NARTEX }\end{array}$ & FAÇADE \\
\hline $\begin{array}{l}5 \text { - TRANSVERSAL VIBRATION OF THE NAVE } \\
6 \text { - SHEAR MECHANISMS IN THE SIDE WALLS } \\
7 \text { - LONGITUDINAL RESPONSE OF THE } \\
\text { COLONNADE } \\
8 \text { - VAULTS OF THE NAVE } \\
9 \text { - VAULTS OF THE AISLES }\end{array}$ & NAVE \\
\hline $\begin{array}{l}10 \text { - OVERTURNING OF THE TRANSEPT'S END } \\
\text { WALL } \\
11 \text { - SHEAR MECHANISMS IN THE TRANSEPT } \\
\text { WALLS } \\
12 \text { - VAULTS OF THE TRANSEPT }\end{array}$ & TRANPSEPT \\
\hline $\begin{array}{l}13 \text { - TRIUMPHAL ARCHES II TRIUMPHAL ARCH } \\
14 \text { - DOME AND DRUM } \\
15 \text { - LANTERN }\end{array}$ & DOME \\
\hline $\begin{array}{l}16 \text { - OVERTURNIG OF APSE } \\
17 \text { - SHEAR MECHANISMS IN PRESBITERY AND } \\
\text { APSE } \\
18 \text { - VAULTS IN PRESBITERY AND APSE }\end{array}$ & APSE \\
\hline $\begin{array}{l}19 \text { - PART OF ROOF: SIDE WALLS OF NAVE AND } \\
\text { AISLES } \\
20 \text { - PART OF ROOF: TRANSEPT } \\
21 \text { - PART OF ROOF: APSE AND PRESBITERY }\end{array}$ & $\begin{array}{c}\text { ROOF } \\
\text { COVERING }\end{array}$ \\
\hline $\begin{array}{l}22 \text { - OVERTURNING OF THE CHAPELS } \\
23 \text { - SHEAR MECHANISMS IN THE WALLS OF } \\
\text { CHAPELS } \\
24 \text { - VAULTS OF CHAPELS } \\
25 \text { - INTERACTIONS NEXT TO IRREGULARITIES }\end{array}$ & CHAPEL \\
\hline $\begin{array}{l}26 \text { - PROJECTIONS (DOMED VAULTS, PINNACLES, } \\
\text { STATUES) } \\
27 \text { - BELL TOWER } \\
28 \text { - BELL CELL }\end{array}$ & BELL TOWER \\
\hline
\end{tabular}

Table 2. Damage Mechanisms and Part of a church building. 
Moreover, it is necessary to organize and structure the model (both geometric and semantic) in a suitable way, with the segmentation into the specific architectural elements or groups of them.

It is precisely for this reason that in the DB of the ResCult project a deepening part was added regarding the description employed by the structural study of historic buildings and the data attributable both to the seismic risk category and to the damage mechanisms.

Considering the subdivision in macro-elements of the model, and the subsequent associated information and data, this methodology allows to relate and archive the damage modes and the collapse mechanisms, classified as 28 damage mechanisms (Lagomarsino and Podestà, 2004c) (Table 2).

\subsection{The directive features in the data model extension}

In this framework, the Department of Italian Civil Protection and the Ministry of Cultural Heritage and Activities and Tourism (MiBACT) have developed, following the Directive of 2011, a Damage Form, to represent and document the churches and every traditional masonry building behaviours after a seismic event. The behaviours of the masonry churches, indeed, could be represented by a series of mechanisms, that are currently manifested both for different epochs and different construction system. The working group proposed an updated 'Form for documenting churches', named Model A-DC, first approved by the Italian Decree of the President of the Council of Ministers 2006, then updated and re-approved in 2011.

The Model A-DC is divided into two sections: the first part contains the general information of the building (A1-A13), while the second part contains the list of the 28 collapse mechanisms for the churches; for each mechanism, the most frequent damage modalities (level of damage) are shown.

The damage modalities are classified in 6 levels, similar to those present in the EMS98 European macro-seismic scales and used in the survey vulnerability methods for ordinary buildings ${ }^{1}$ : 0 -no damage; 1-light damage; 2-moderate damage; 3-serious damage; 4-very serious damage; 5-collapse.

A part of the model we propose, which is not expressly stated in the directive, regards the possibility to archive different values of the level of damage. This necessity arose from the interdisciplinary work with structural engineers, which noticed how the value of the level of damage can change with the depth of the analyses carried out. In particular, a first, coarser, value of the level of damage can be stated by means of the simple observation performed by an expert, which is already quite reliable, but, obviously, the value can change when a detailed 3D model, realized from dense survey measurement data, is employed for the artefact observation ( ${ }^{\text {nd }}$ level). Even more, if a specific static modelling is performed using as base the surveyed 3D model a $3^{\text {rd }}$ level can be stated. Therefore, three attributes are added: 'DamageLevel1' for values from observation, 'DamageLevel2' for values obtained from the 3D model, 'DamageLevel3' from specific structural monitoring and analyses.

This was made possible thanks to an interdisciplinary approach of research disciplines ${ }^{2}$; during the evaluation of different parameters or attributes of an architectural heritage it is possible to obtain information, both before and after the 3D metric survey, especially for identifying the different importance of its damage mechanisms.

\footnotetext{
1 Also in agreement with the guidelines of the National Group for the Defense from Earthquakes- GNDT.

2 These proposals aiming to integrate the analysis model are the result of an interdisciplinary discussion with D. Sabia and R. Lancellotta from
}

\section{RESCULT DB CONCEPTUAL MODEL EXTENSION AND GEOMETRICAL IMPROVEMENTS}

Starting from the ResCult conceptual model a new extension was developed (Fig. 4). Taking into account the typical structure of a basilica church and its segmentation into macro-elements, some attributes and entities were added. To test the methodology, the case study of St Nicola Church in Tolentino (Italy) was chosen.

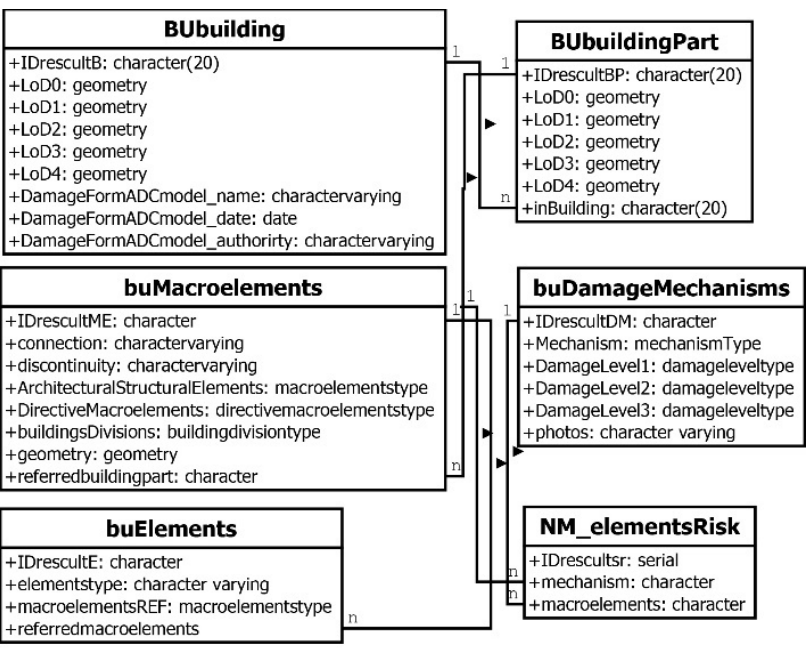

Figure 2. Proposed extension of the ResCult conceptual model.

An updated data model was planned to develop the database structure with the object-relational database management system (ORDBMS) PostgreSQL - PostGIS.

Since the Macro-Elements are a segment of the building, an extension of the BuildingPart of INSPIRE Consolidated UML Model was considered for representing them. The BuildingPart INSPIRE "featureType" Class is part of the Annex III Theme in the Building3D schema; it is identified as a "sub-division of a Building that might be considered itself as a building”. (INSPIRE, 2011).

Firstly, the entity "Building” was extended adding the attributes related to the Model A-DC ( $\S 3.2$ ), the model that inherit the standards from the latest-updates of the Directive for the church mechanisms. Name, date and authority attributes were added to link the Form to the Church Building; it is connected to the "BuildingPart" inasmuch both "Building" and "BuildingPart" inherit the attributes from the general table "AbstractConstruction" (Figure 2).

After that, the table "Macroelements" was created to define a specific entity for the 3D geometries of the church. It identifies the structural architectural elements, sometimes grouped and sometimes not, according to Table 2 , and its related fields.

The Macro-elements feature contains connection and discontinuity attributes which represent links and disunions between structural-elements and non-structural elements, which can influence and amplify the damage mechanisms. The attribute directiveMacroelements derives from the classification shown in Table 2. The other fields, named architecturalStructuralElements (macroelements_type) and buildingsdivisions (buildingsdivision type), represent the identification of the Macro-Element type according to the AAT Getty Vocabularies standard, in order to represent the elements and parts of the church, as conceived in the Directive updates.

Politecnico of Turin, also documented by a msc thesis: Pascale A., Seismic analysis of the St. Nicholas Church in Tolentino, 2017, Tutors: Sabia, Spanò. 
Principally, for this research a part of the AAT was considered to obtain a shared definition of the architectural parts in which the architectural heritage was segmented. In this way, macroelements of the built heritage were managed and spread without inconsistencies in description and standard definitions.

The types to define these vocabularies were created in PostgreSQL as a codelist “enumeration”, a list of every typology of Macro-Elements and Building Spaces according to the AAT. In particular, the sub-terms of the AAT categories Object Facet - Components - Components by specific context were considered. After that, other two sub-hierarchical classifications were selected: the first one concerns the building spaces, Building divisions - Rooms And Space - Religious Building Spaces Christian Religious Building Spaces, for representing the parts of the church, which is the type of building we refer to (e.g. 'aisles', 'chapels', 'transept', 'nave', and so on). The second one is adopted to represent the buildings elements, Architectural elements - Structural Elements - Enclosing Structural Elements or Supporting And Resisting Elements, for archiving the information about the structural parts of the building (e.g. 'walls', 'dome', 'vaults', 'columns', and related sub-categories).

In Figure 3 it is possible to view the other sub-hierarchical classes.
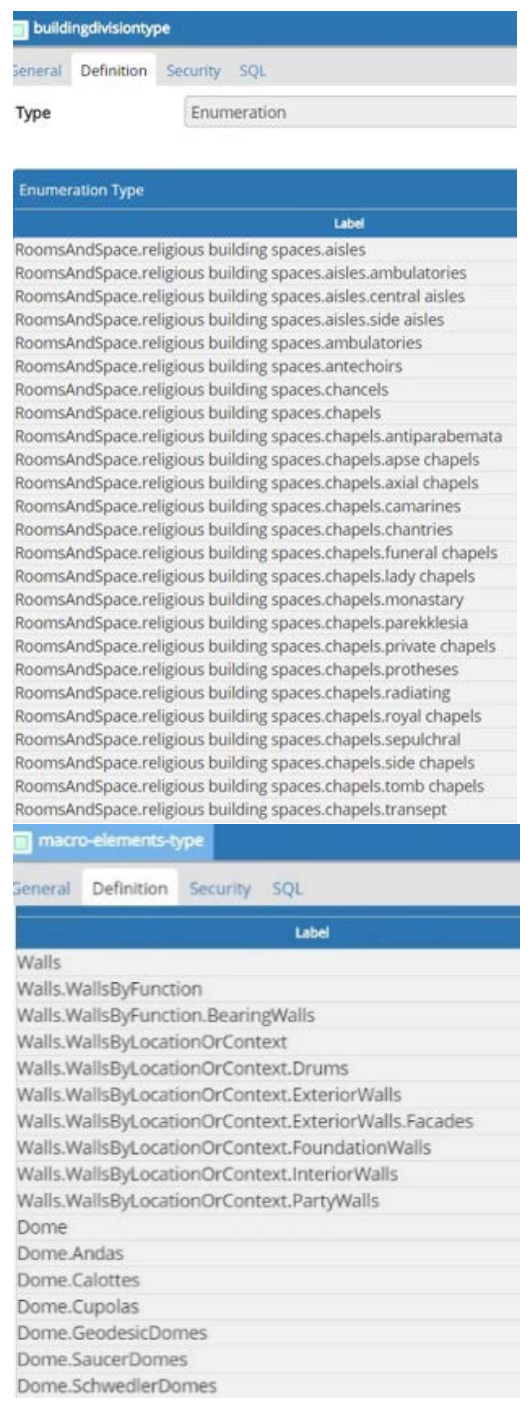

The use of the Getty thesaurus, compliant with the CIDOC-CRM, makes possible the identification of the single macro-element connected with the space in which it is located, this choice was made considering the classifications outlined in the Directive and in its latest-updates.

After that, the table "Elements", which represents the segmentation of Macro-elements, was created and connected with the entity "Macroelements". To make effective the study presented, the geometric Macro-Elements of the 3D building were linked to the "DamageMechanisms" table, with a relation many-to-many.

The damage mechanisms, as it is reported below, represent the effects of a seismic event with a level of damage indicator. In the attributes, there is the possibility to store the type, the three damage level (§ 3.2), and a field is added to link the photos of the damage. The object table "DamageMechanisms" contains as attribute an enumeration codelist type, named mechanismtype, for identifying the 28 different mechanisms (Table 2).

After the filling of the DB, the macro-elements geometries can be queried in QGIS in order to know all the information related to them; the relations between entities and information about damage mechanisms, can be queried

\section{THE EXTENSION APPLIED ON THE ST. NICOLA CHURCH IN TOLENTINO, ITALY}

The St. Nicola Church is one of the most important religious and cultural complexes of Central Italy. The whole city of Tolentino and the church were slightly damaged by the seismic wave that hit this area of Italy starting from the 24 August 2016 and that culminated the 30 October 2016, with a seismic shock of magnitude 6.5. However, the two replicas that interested Tolentino took place on 26 October 2016 with epicentres on the Umbrian-Marche border.

The religious complex is still closed to the public due to security reasons, damage assessment and restorations. For analysing the damages and assessing the need of structural intervention on the churches, several dynamic monitoring and studies on structural stability were performed, employing various methods. (Sabia et al. 2017). Some of these methods foresee the use of a 3D model built from a surveyed $3 \mathrm{D}$ point cloud, which permits the achievement of higher accuracies.

From the same data, we started modelling the 3D geometries to be archived and managed into the GIS.

For the construction of the 3D model, an accurate and georeferenced 3D survey was conducted in 2017 by the geomatics group of the Politecnico di Torino.

During this survey topographic methods (Total Station, GPS / GNSS) and image-based and range-based techniques (Unmanned Aerial Vehicle - UAV Photogrammetry, LIDAR and SLAM Simultaneous Localization And Mapping technologies) were employed in an integrated approach, as usual. Among the photogrammetric method the use of low cost $360^{\circ}$ image-systems (GOPRO ring) and steadycam stabilized (DJI Osmo) was experimented

The used methods guaranteed a complete acquisition of the architectural complex and their integration it was useful to obtain complete and high detailed point model, representing the outside environment with an accuracy of few centimeters $(5-6 \mathrm{~cm})$ and the inside environment with an accuracy of 1-2 centimeters. (Figure 4) (Costanzo et. al, 2018).

Figure 3. Extract of the codelist filling the attribute

buildingdivision_type' and 'macroelement_type', derived from the Getty AAT vocabulary 


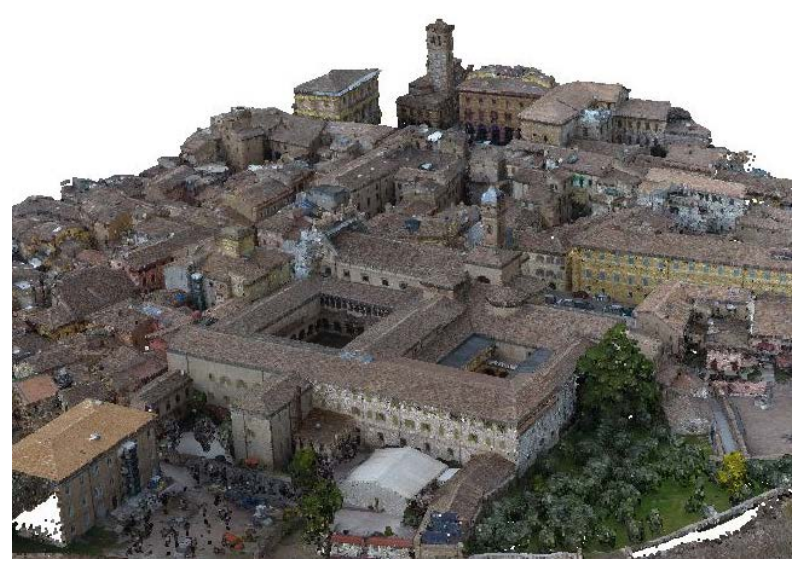

Figure 4. 3D point cloud obtained from the integrated survey.

\section{THE DEFINITION OF THE 3D MODEL AND ITS SEGMENTATION}

The 3D model of the Saint Nicola Church in Tolentino, created to populate the Rescult EID, derives from the 3D metric survey (§ 5.) performed with a high level of detail scale.

The generation and the visualization of 3D geometries connected to a database and the need to query these geometries contained in a complex relational model, implicate serious interoperability problems among the tools available today. For this reason, it was necessary to operate using different software and formats, in order to guarantee an effective data interoperability.

After the point model filtering and optimization, a 3D model was generated in Autocad (by Autodesk), with 3D polygons, and exported in .dxf. However, this solution gave some problems of interoperability for the visualization once imported in ArcScene (by ESRI): it was possible to see the centroids of geometric features, but not the geometries themself.

So, it has been decided to import the 3D .igs file (IGES) from Autocad, in 3DReshaper (by Technodigit), allowing the conversion of the solid geometry in polygonal mesh and exporting again in .dxf from this software. Finally, the mesh was imported in ArcScene (by ESRI). The GIS platform recognises the model as a Multipatch geometry, represented by points, polygons and polylines. After the database creation, the model entity was populated in QGIS, importing the Multipatch shapefile from ArcScene. To insert the geometry of the model (multipolygon format) in PostGIS it has been necessary to set the geometry type in PostgreSQL as "geometry MultyPolygonZ".

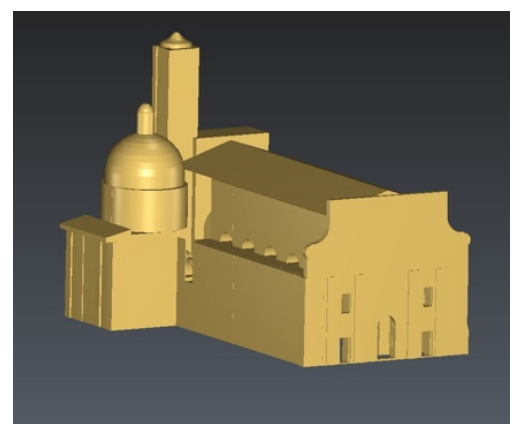

Figure 5. 3DReshaper mesh visualisation.

After having obtained the model, it has been possible to subdivide the geometries according to the macro-elements (Fig. 6), as described in paragraph 3.1, and associate the information to each of them.

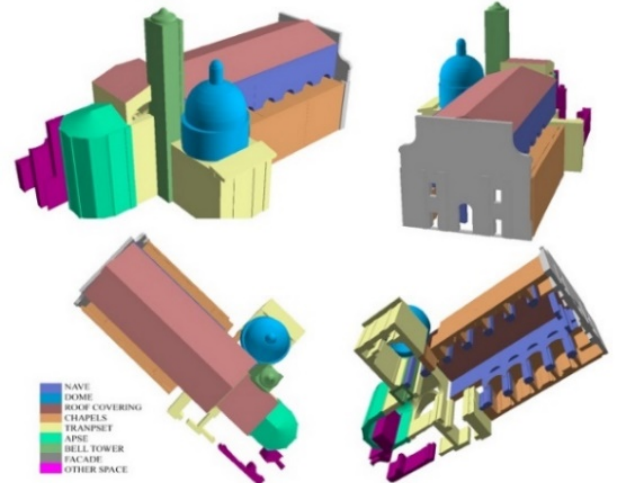

Figure 6. Building segmentation in Macro-elements according the Directive (2011).

The model has been segmented, thanks to the studies performed in collaboration with the group of structural engineers of the Politecnico of Turin (Prof. D. Sabia and prof. R. Lancellotta), following the latest updates of the Directive, in the 8 macroelements plus another one which includes some bearing walls connecting the church with the nearby cloister.

\subsection{GIS 3D and data visualization}

To visualise and to query the geometry model, the Postgres database was connected with its relations in the GIS software: QGIS.

Firstly, it is possible to visualise every LoD of the case study of Tolentino, starting from a general map view of the urban context of the city. In the LoD 0 (Figure 7a) the DTM (Digital Terrain Model), roads, hydrography and buildings are represented (in 2D): these data are taken from the CRT 302160 .dwg drawing map of Tolentino (1:10k).

In the LoD 1 (Figure 7b) the St. Nicola Church and its context, in 2.5D are shown; these data derive from the DSM (Digital Surface Model), elaborated after the aforementioned survey campaign data acquisition. The LoD 2 represents the 3D geometry of the church with the roofs (Figure 7c), derived directly from the point cloud. Whereas in LoD 3 and LoD 4 it is possible to create a model with detailed wall and roof structures with the further addition of interior structures.

Moreover, thanks to a proper entity table of the DB, "Coverage", connected with the risk and hazard, it is possible to view the raster map of the seismic Micro-zonation in this area (Figure 7d).

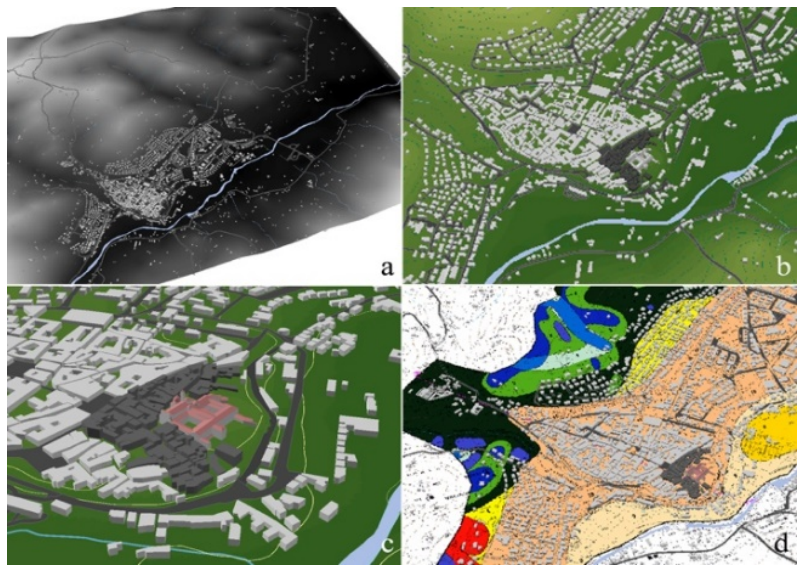

Figure 7. LoD visualisation in ArcScene.

The Macro-element 3D model is visualised in QGIS 3.2 using its new extension "3D map". After adding in QGIS the spatial 
entities of the EID, it is possible to define the style and the properties of the 3D visualization, assigning the DTM of the Marche Region as terrain.

Afterwards, it is also possible to query the elements through the 2D map and to select and display them in the 3D map (Figure 8). Then, opening the attribute table it is possible to visualise and query the relations between the tables of the database objects. In this way, it is possible to identify, for each macro-element, one or more damage mechanisms associated to it, the connections, the discontinuities and the three damage levels.

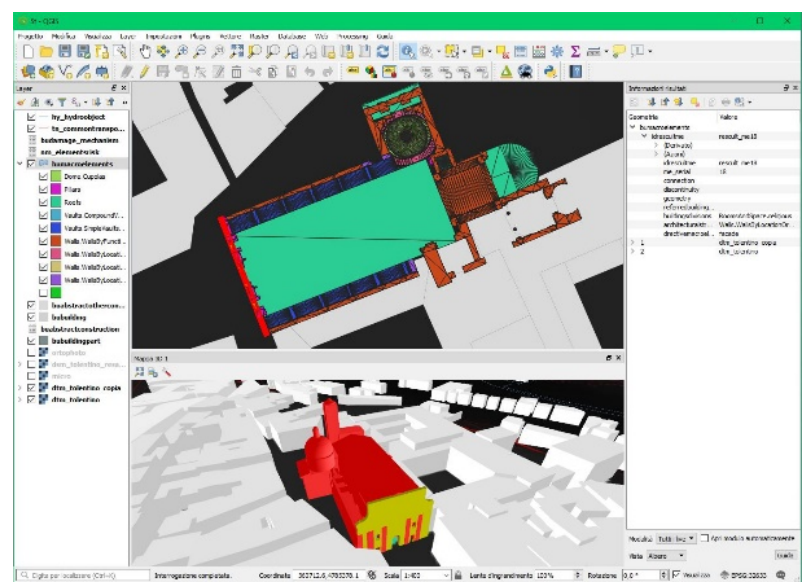

Figure 8. Façade macro-element query and 3D visualization in

QGis 3.2. The macro-elements "Façade" is related to the mechanism "M1. Overturing of the façade", to which the three

levels of damage correspond. In the Saint Nicola church, a

serious damage level was assigned by means of visual

observation by structural expert, but afterwards, only a

moderate damage level was assigned from both 3D metric

detailed model assessment and other specific structural analysis.

In Figure 9 (below), a query applied to the façade object is shown, it is possible to visualise the mechanism associated to the ID of the "Macroelements" table. Finally, querying the attribute table "DamageMechanisms" (using the Evis database plugin) it is possible to view the associated photos related to the object or to their damages (Figure 10).

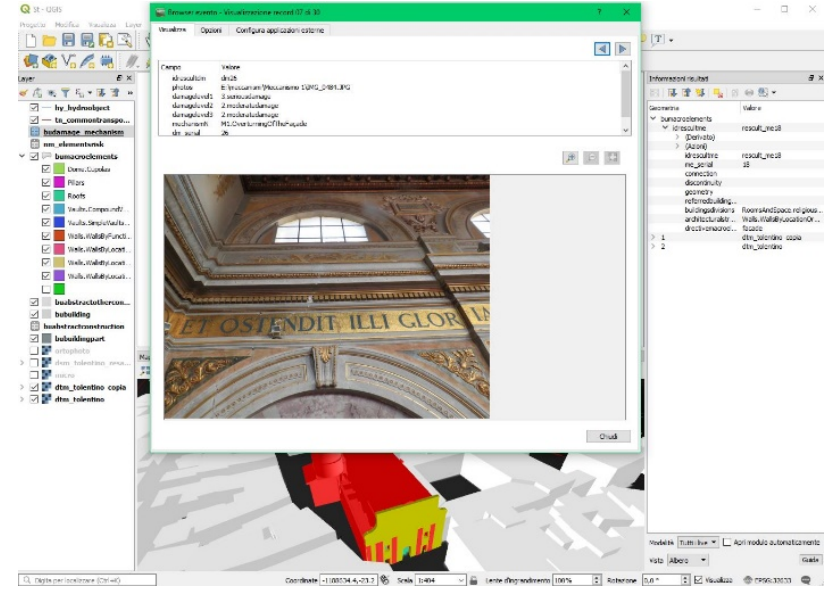

Figure 10. Façade mechanism "photos" attribute query.

\section{CONCLUSIONS}

The proposed method allows to archive in a multi-scale database 3D information with a very high level of detail about architectural heritage. This is fundamental for supporting experts studying the damages of seismic events on historical buildings, consisting in masonry structures. The possibility to store also the results of structural analysis in the database is helpful for preventing further damages through specific actions and interventions.

The use of standard data model permits the interoperability with the available maps, which, in Europe, should be INSPIRE compliant by 2020.

From these ones, also the information about the specific hazard of the area and the parameters deriving from the characteristics of the context can be extracted. Especially, using the ResCult INSPIRE extension. Many passages through different software tools are needed in the framework for processing the point cloud, building the 3D model, segmenting the 3D model, importing it into the database and visualizing and querying it. The reduced interoperability that sometimes still exists between different software make a careful and often articulated workflow unavoidable. Some difficulties are also linked to the management of the same reference systems by some software.
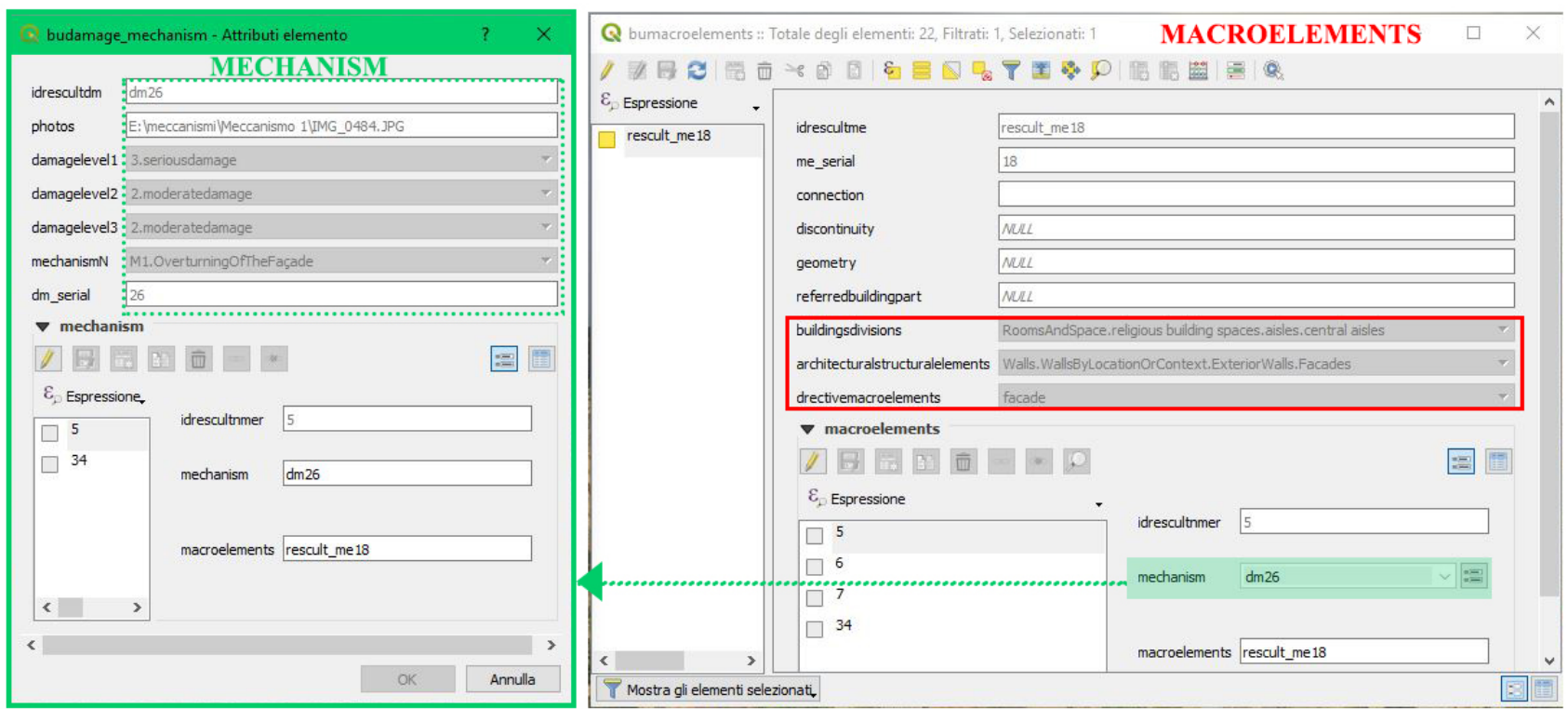

Figure 9. Façade macro-element attributes table information and its relationship with mechanisms attributes. 
However, the possibility to exploit such detailed archive give great advantage when developing prevention plans against earthquake disasters and can be a great opportunity to foster preservation of architectural heritage.

Nowadays, the importance to develop the research to solve the interoperability problems is recognized. For overcoming these issues, the current trend of software development is moving towards this topic, according to the needs of the researchers in this field. The future developments of this research, for example, can be improved thanks to the new extension of the next version of QGis (3.4). It will be possible to query the 3D model directly from the 3D map and to categorize the style of the different geometries by means of rules.

\section{ACKNOWLEDGEMENTS}

The ResCult Project, of which the present study is a part, was developed with the partners: SITI, Corila/IUAV, UNISDR, SDIS04, TUB, POLITO. The 3D data of the San Nicola church in Tolentino, employed for the application, were surveyed by the Team DIRECT of the Geomatics group of Politecnico of Turin.

\section{REFERENCES}

Biljecki, F., Ledoux, H., Stoter, J., 2016. An improved LOD specification for 3D building models. Computers, Environment, and Urban Systems, vol. 59, pp. 25-37.

Blaško, M., Cacciotti, R., Křemen, P., Kouba, Z., 2012. Monument damage ontology. In: Progress in Cultural Heritage Preservation. Springer Berlin Heidelberg. pp. 221-230.

Cacciotti, R., Valach, J., Kuneš, P., Čerňanský, M., Blaško, M., Křemen, P., 2013. Monument damage Information System (MONDIS), An Ontological Approach to Cultural Heritage Documentation. In ISPRS Annals of the Photogrammetry, Remote Sensing and Spatial Information Sciences, 2(5), pp.5560 .

Chiabrando, F., Colucci, E., Lingua, A., Matrone, F., Noardo, F., Spanò, A., 2018. A European Interoperable Database (Eid) to Increase Resilience of Cultural Heritage, Int. Arch. Photogramm. Remote Sens. Spatial Inf. Sci., XLII-3/W4, pp. 151-158.

Costamagna, E., Spanò, A., 2012. Semantic models for architectural heritage documentation. In: EuroMed 2012: Progress in Cultural Heritage Preservation, LNCS Book Series, Springer Verlag ISBN: 978-3-642-34234-9, pp. 241-250.

Costanzo, D., Chiabrando, F., Lancellotta, R., Lingua. A., Sabia, D., Spanò, A., 2018. Rilievo 3D e monitoraggio strutturale per l'analisi post-sisma del complesso di S. Nicola a Tolentino (MC), XXI National conference ASITA, pp. 21-23 November 2017, Salerno, Italy.

Doerr, M., Ore, Ch.E., Stead, S., 2007. The CIDOC Conceptual Reference Model - A New Standard for Knowledge Sharing. In: Tutorials, posters, panels and industrial contributions at the 26th International Conference on Conceptual Modeling. ACS. 83. pp. 51-56.

Fernández-Freire, C., del-Bosque-González, I., Vicent-García, J. M., Pérez-Asensio, E., Fraguas-Bravo, A., Uriarte-González, A., Fábrega-Álvarez P., Parcero-Oubiña, C., 2013. A Cultural Heritage Application Schema: Achieving Interoperability of Cultural Heritage Data in INSPIRE. IJSDIR, 8, pp. 74-97.
Giuffrè, A., 1993. Sicurezza e conservazione dei centri storici in zona sismica. Il caso di Ortigia. Laterza, Bari.

Integrated Research on Disaster Risk, 2014. Peril Classification and Hazard Glossary (IRDR DATA Publication No. 1). Beijing: Integrated Research on Disaster Risk. http://www.irdrinternational.org/wpcontent/uploads/2014/04/IR DR_DATA-Project-Report-No.-1.pdf (12 May 2018).

Lagomarsino, S., Podestà, S., 2004. (a) Seismic Vulnerability of Ancient Churches: I. Damage Assessment and Emergency Planning, 2004. Earthquake Spectra, Volume 20, No. 2, pp. 377-394, May 2004.

Lagomarsino, S., Podestà, S., 2004. (b) Seismic Vulnerability of Ancient Churches: II. Statistical Analysis of Surveyed Data and Methods for Risk Analysis.

Lagomarsino, S., Podestà, S., Cifani, G., Lemme, A., (c) 2004. The 31st october 2002 earthquake in molise (italy): a new Methodology for the damage and seismic Vulnerability survey of churches, 13th World Conference on Earthquake Engineering, Vancouver, B.C., Canada, August 1-6, 2004.

MIBACT (Ministero dei Beni e delle Attività Culturali e del Turismo), Model A-DC.

http://www.beniculturali.it/mibac/multimedia/MiBAC/documen ts/1338454237471_allegato4.pdf (25 May 2018).

NIKER (New Integrated Knowledge Based Approaches to the Protection of Cultural heritage from Earthquake-induced Risk), 2010. Inventory of earthquake-induced failure mechanisms related to construction types, structural elements, and materials, Deliverable 3.1,

http://www.niker.eu/assets/Files/Download/D3.1\%20-

\%20Annex1\%20-\%20Damage\%20Abacus.pdf (13 May 2018).

Noardo, F., 2017. A spatial ontology for architectural heritage information. In: Grueau, C., Gustavo Rocha, J., Laurini, R., GISTAM 2016 - Revised Selected Best Papers, CCIS Book Series, Springer Verlag, ISSN: 18650929, ISBN: 978-3-31962618-5 vol. 741, pp. 143-163.

Ohori, K. A., Krijnen, T., Ledoux, H., 2017. Developing a CityGML/IFC interface to integrate BIM model with Geo models, https://3d.bk.tudelft.nl/projects/geobim/ (12 May 2018).

Papa, S., Di Pasquale, G. Presidenza del Consiglio dei Ministri - Dipartimento della Protezione Civile, 2013. Manuale per la compilazione della scheda per il rilievo del danno ai beni culturali, Chiese Model A - DC.

http://www.awn.it/component/attachments/download/1247, (25 May 2018).

Sabia, D., Aoki T., Costanzo, D.,Lancellotta, R., Quattrone, A., 2017. Post-earthquake dynamic monitoring of Basilica of St. Nicholas of Tolentino, Proccedings of ANIDIS 2017.

UNISDR, 2009. Terminology on Disaster Risk Reduction. ISDR, International Strategy for disaster reduction. United Nations.

UNISDR, 2017. Disaster-related Data for Sustainable Development. Sendai Framework for Disaster Risk Reduction 2015-2030. Data Readiness Review 2017. Global Summary Report. 